\title{
LAS INTERRELACIONES HISTORIA Y CINE, EN ESPAÑA
}

\author{
INTERRELATIONSHIP HISTORY AND \\ CINEMA, IN SPAIN
}

Josep Maria Capparós Lera*

Resumen: La normalización del empleo del cine como fuente histórica y medio didáctico en España ha sido la "travesía del desierto". Se inició en 1974 y empezó a ser admitida a finales del siglo XX. Este artículo es una panorámica histórica de un objetivo logrado.

Palabras clave: Cine. Historia. Films históricos. Centre d'Investigacions Film-Història.

\begin{abstract}
The normalization of the employment of the cinema as historical source and didactic way in Spain has been the "voyage of the desert". It began in 1974 and started being admitted at the end of the 20th century. This article is the panoramic historical one of a successful aim.
\end{abstract}

Keywords: Cinema. History. Historical Films. Centre d'Investigacions FilmHistòria.

Que el arte cinematográfico es una fuente histórica, hoy nadie lo duda. Pero hasta que el maestro Marc Ferro - reconocido especialista de la escuela de los Annales - no lo consolidó en el mundo académico, fue una materia muy discutida entre los historiadores contemporáneos. ${ }^{1} \mathrm{Y}$ en España, tuvo que pasar más una década para que las interrelaciones entre la Historia y el Cine se hicieran un hueco en las Universidades.

* Director del Centre d'Investigación Film-Història. Profesor Catedrático de Historia Contemporánea y Cine de la Universitat de Barcelona. E-mail: jmcaparros@ub.edu 
No obstante, casi paralelamente a que se publicara el primer estado de la cuestión sobre estas relaciones Historia-Cine en el mundo ${ }^{2}$, un joven profesor universitario español defendía una tesis doctoral titulada El cine, fuente histórica del siglo $X X{ }^{3}$ Con este trabajo y su importante labor posterior, el profesor Ángel Luis Hueso Montón ${ }^{4}$ se transformaría en el pionero en nuestro país del campo especializado que nos ocupa.

Pero en 1976 surgiría en Barcelona una iniciativa más próxima a la docencia cinematográfica - el empleo del film como medio didáctico - que a la utilización del cine como fuente auxiliar de la ciencia histórica. Se trataba de la cooperativa Drac Màgic que, desde entonces, ha desarrollado numerosos ciclos de Historia a través del film ${ }^{5}$, dirigidos especialmente a alumnos de Bachillerato -hoy Enseñanza Secundaria- y preuniversitario. La tarea pedagógica de este grupo de especialistas se complementaría asimismo con la edición de una serie de dossiers a fin de ofrecer alternativas didácticas a profesores y alumnos de las diversas escuelas que asisten a las proyecciones de los films históricos. ${ }^{6}$

1977 fue un año fructífero en torno al lanzamiento de las actividades sobre Historia y Cine en España. Durante el verano, la Filmoteca Nacional y la Fundació Joan Miró de Barcelona organizaron un extenso ciclo titulado "Cine e Historia", que sería la primera aproximación al tema en nuestro país. Se exhibió una muestra de 52 películas clásicas, de género. ${ }^{7}$ Después, la Filmoteca Española organizaría otros ciclos más específicos: "El cinema de propaganda política en la República de Weimar", "La Edad Media en el cine", "El camino hacia el III Reich" y "La Guerra Civil española”, que seguirían hasta hoy. Y, casi a continuación, el Festival Internacional del Cine de San Sebastián, en su edición de 1977, organizó una mesa redonda sobre "El film como testimonio histórico", en la cual participaron profesionales del medio: Joris Ivens, Freddy Buache, Román Gubern, Jaime Camino, Elías Querejeta, Ricardo Muñoz Suay y Pere Fages. ${ }^{8}$

En octubre del mismo año 77, en Córdoba se celebró la I Semana Internacional de Cine Histórico - donde fui invitado como miembro del Jurado y para presentar el ciclo sobre el cine de la II República española9'-; certamen especializado que sólo alcanzó cuatro ediciones y tuvo una continuidad aislada -y prácticamente fallida, por su poco eco y desaparición- en el Festival de Cine Histórico de León.

Ese mismo curso académico 1977-78, el Instituto de Ciencias de la Educación de la Universidad de Barcelona incluyó en el programa del CAP (Cursos de Adaptación Pedagógica para el Profesorado) una asignatura titulada "Didáctica de la Historia a través del Cine", encargándole al que suscribe la docencia. De ahí que en 1981, editara un cuadernillo sobre mis cursos de cine en el ICE. ${ }^{10}$ 
De abril a junio de 1978, el Cine-Forum Caspe (del Colegio de los Jesuitas, de Barcelona) organizó un primer ciclo sobre "Cinema e Historia Contemporánea", con un programa de once películas clásicas. Mientras que en el mes de diciembre del mismo año, la Obra Cultural de la Caixa de Pensions, de Palma de Mallorca, iniciaba sus "Semanas de Cinema Histórico", en colaboración con la Universidad balear. ${ }^{11}$

Asimismo, en enero-febrero del siguiente año, la Escola Popular organizó un ciclo de "Cinema i Història", bajo el patrocinio del Patronato de Cultura de Cornellà de Llobregat (Barcelona), con la colaboración de la revista de historia $L$ 'Avenç, editando un folleto.

Con todo, hasta el curso académico 1979-1980 no entraron oficialmente las relaciones Historia-Cine en la Universidad española. Fue el citado pionero Ángel Luis Hueso quien inició un breve ciclo en la Universidad de Santiago de Compostela (abril 1980), para en años sucesivos continuar tales proyecciones especializadas sobre temas monográficos: "Cine español y siglo XX”, "Los años treinta", "La mujer en el cine", "Mundo obrero y cine", "Cine político", "Novela española y cine", "Grandes obras de los años 20", etc. ${ }^{12}$ Aun así, el autor del presente artículo iniciaría también ese mismo curso académico las "Primeres Jornades d'Història i Cinema", en la Facultad de Geografía e Historia de la Universidad de Barcelona, las cuales tendrían continuidad hasta el año $1989 .{ }^{13}$

Por otra parte, desde 1981 la Universidad Autónoma de Barcelona, en colaboración con el Ayuntamiento de Sabadell, también se incorporó a estas tareas especializadas con el denominado "Cicle interdisciplinar de Cinema", que siguieron en cursos posteriores. ${ }^{14}$ Pero más importante fue la manifestación que organizó en Barcelona el Colegio de Doctores y Licenciados de Cataluña -siguiendo la tradición de los Encontres especializados de Perpignan y Valence (Francia)-: la "I Semana de Cine, Historia y Enseñanza", con la participación de diversos pedagogos e historiadores extranjeros ${ }^{15}$, mientras la Filmoteca de la Generalitat proyectaba un ciclo durante los mismos días del mes de marzo de 1982.

Un año después, esta Filmoteca catalana programa nuevamente una Setmana de Cinema \& Història, con participación del documentalista Ivor Montagu. Y el mismo mes de marzo de 1982 insistió sobre el tema, con la organización de un seminario sobre Cinema e Historia: La Alemania nazi, dirigido por el profesor Karl Friedrich Reimers (Universidad de Munich), con la colaboración del Instituto Alemán de Cultura, de Barcelona.

Y llegamos a 1983, para seguir la cronología. La Facultad de Filosofía y Letras de la Universidad de Tarragona (ahora Rovira i Virgili), en colaboración con el Departamento de Filología Clásica de la Universidad Autónoma, monta el I Ciclo de Cine Histórico, dedicado a El Món Romà, y los organizadores 
editan dos años después las Actas en un libro especializado: Pere-Lluís Cano \& Joan Lorente-Costa, Espectacle, amor $i$ martitis al cinema de romans. ${ }^{16}$

Al mismo tiempo, el ICE de la Universidad de Barcelona y el Estudi General de Lleida inician unas Jornadas de Cine, Historia y Literatura dedicadas a Guerra i Revolució, dentro del marco del Departamento de Historia Contemporánea, en diciembre de $1983 .{ }^{17}$

Pero 1983 es también el año del nacimiento del Centre d'Investigacions Film-Història ${ }^{18}$, entidad fundada por el autor de este artículo, con la colaboración de diversos profesionales del cine (especialmente, los profesores Rafael de España y J. A. Soler Carreras, o futuros cineastas como Edmon Roch), de la cual hablaremos más adelante. No obstante, ese mismo año este Centro especializado en las relaciones Historia-Cine produce un vídeo educativo titulado Historia del Cine. Época muda (1895-1930), con un libro adjunto, en versión castellana y catalana, de 90 minutos de duración. ${ }^{19}$

1984 será otro año fructífero para las interrelaciones Historia y Cine, en España. El referido grupo Drac Màgic imparte un Curso de Cine e Historia, en el Colegio de Doctores y Licenciados, que tendrá continuidad. Además, su director dará a luz el primer libro especializado poco después: José Enrique Monterde, Cine, historia y enseñanza. ${ }^{20} \mathrm{El}$ profesor Monterde, por tanto, puede considerarse otro de los pioneros de esta materia en nuestro país.

Por otro lado, el ICE de la Universidad Autónoma de Barcelona organiza en la Delegación de Gerona (hoy Universidad de Girona) una experiencia pedagógica importante, dentro de la línea iniciada por la cooperativa Drac Màgic, y editan un dossier titulado Materials d'Història i Cinema (para el curso interdisciplinario del Curso de Orientación Universitaria). ${ }^{21}$ Al tiempo que el Institut Français de Barcelona dedica uno de sus habituales ciclos de cine a Figures heroïques de Moyen Age, que presentará el especialista Marcel Oms. ${ }^{22}$

Mientras, en 1985 la Universidad de Murcia se incorpora a este campo especializado en una sección de su Semana de Cine Español, con la participación del citado pionero Ángel Luis Hueso; ${ }^{23}$ al mismo tiempo la Universidad de Salamanca organiza el primer ciclo de Cine e Historia, por iniciativa de la Delegación de Alumnos de la Facultad de Geografía e Historia, que incluso edita un libro introductorio.

En marzo de 1986 fueron dos las actividades que se realizaron en el presente terreno: la Primera Mostra de Cinema Històric i Documental, que llevaron a cabo el Ayuntamiento de Tortosa y la Diputación de Tarragona; y el ciclo Cine e Historia, que organizó la Universidad de Valencia a través de su "Aula de Cinema".

Pero en septiembre del mismo 1986 - producto de mi referido seminario sobre Interrelaciones Historia y Cine - surgen las tres primeras tesinas de licenciatura: El film en la enseñanza de la Historia, de Pablo Bonell Goytisolo; 
El documental de reconstitució històrica: anàlisi de "Retablo de la Guerra Civil española” (1980), de Basilio M. Patino (segons la metodología de Marc Ferro), original de Antoni Rigol i Mach; y Las Hurdes, medio siglo después. Análisis histórico-documental del film de Luis Buñuel (1933), de Josep Maria Avilés, las cuales obtuvieron la máxima calificación en la Universidad de Barcelona.

En 1987, el Centre d'Investigacions Film-Història (a partir de ahora, citado como FILM-HISTORIA) organiza las Primeres Jornades de Cinema en Viu, con la colaboración del Departament de Cultura de la Generalitat de Catalunya: se exhiben obras maestras del cine mudo, sonorizadas a piano por el maestro Joan Pineda y presentadas por reconocidos críticos catalanes.

Aun así, más importante fue la beca que recibió FILM-HISTORIA del Comité Conjunto Hispano-Norteamericano, para impartir sendos cursos de Cine Español en las Universidades de Nuevo México (Albuquerque) y Texas (Austin), que permitió editar un libro en inglés: J. M. Caparrós-Lera \& Rafael de España, The Spanish Cinema: An Historical Approach ${ }^{24}$ y nos invitaron a visitar los estudios de Hollywood. Poco antes, el primer autor había sido nombrado en el XII International IAMHIST Congress, celebrado en Londres, vicepresidente de la International Association for Media and History (IAMHIST, Oxford), cargo que ostenté hasta 1993. Esta entidad reúne a los principales especialistas en la utilización del cine como fuente histórica y medio de investigación.

A partir de ese año, aunque parezca una inmodestia, FILM-HISTORIA se transformaría en el centro más prolífico en torno a las interrelaciones Historia y Cine, en España, con frecuente participación en congresos españoles y extranjeros. Constataremos sólo los más importantes: ponencia El cine soviético en España durante la Guerra Civil ${ }^{25}$, Le cinéma a L'Espagne démocratique ${ }^{26}$, Fred Zinnemann's "High Noon" (1952): An Anti or Pro-McCarthyism Film?27, además del nuevo curso sobre Cine Español impartido en la University of Southampton, con una Beca Erasmus de la CEE.

En el mes de febrero de 1990, presentamos otra comunicación titulada Spanish Contemporary History on TV: The Tejero's “coup d'Etat”, en el 17 Congreso Internacional de Ciencias Históricas (Madrid) y coordinamos un monográfico sobre "El Cine Histórico", para la revista Historia y Vida. ${ }^{28}$ Asimismo, a principios de 1991, nació la revista especializada Film-Historia, que tomaría modelo de las extranjeras Historical Journal of Film, Radio and Television (Oxford), Les Cahiers de la Cinémathèque (Perpignan) y Film and History (USA). Y durante el curso académico 1991-1992 se defendieron las dos primeras tesis doctorales sobre las relaciones Historia-Cine realizadas en la Universidad de Barcelona: La División Azul en el cine, original de Sergio Alegre, y Cine e Historia Contemporánea: análisis filosófico y ténicolingüístico del film "Metrópolis" (1926, dir. Fritz Lang), de Tamel de Pablos. 
Con todo, ese año 1992 fue nuestra "puesta de largo" con la organización de un primer congreso especializado: International FILM-HISTORIA Conference on War, Film and Society: A Methodological Approach, celebrado en la Universidad de Barcelona, con ayuda institucional. Participaron más de 70 congresistas, españoles y extranjeros, y editamos las Actas al año siguiente, en castellano, catalán e inglés. ${ }^{29}$

En el XI International IAMHIST Congress, celebrado en Amsterdam (julio), presentamos cuatro comunicaciones especializadas -en vídeo e ingléssobre la Primera Guerra Mundial y el Cine Español. Y a la vuelta, coordinamos con el profesor Carl J. Mora un curso titulado The Cinema in Spain, dirigido a profesores extranjeros. A final de año, presentamos en el Centre d'Art Santa Mònica (Barcelona) el primer libro de la colección "Film-Historia": El cine en Cataluña. Una aproximación histórica, que realizamos en equipo. ${ }^{30}$ En 1994, este libro -que editamos en castellano- será también presentado en Madrid por el Delegado de la Generalitat de Catalunya ante el Gobierno español, y el entonces Director de la SGAE. Destacaron al fundador de FILM-HISTORIA como impulsor de una escuela de historiadores especializados al servicio de nuestro país. Asimismo, aparecen las primeras reseñas de películas españolas en la sección de cine que dirige el profesor Robert A. Rosenstone ${ }^{31}$, en The American Historical Review ${ }^{32}$, a cargo de J. M. Caparrós Lera.

Nuevas ponencias de este último profesor en el extranjero: "El maestro de esgrima". Estudio comparativo de la novela de Arturo Pérez-Reverte y el film de Pedro Olea (1992), en CINE-LIT: International Conference on Hispanic Literatures and Cinematographies ${ }^{33}$ y La transición del mudo al sonoro en el cine español. Films hispanos rodados en Joinville-le-Pont (París, 1930-1933), en I Coloquio Internacional de Historia del Cine Iberoamericano. ${ }^{34}$ Por último, ese mismo año coordinamos otro monográfico sobre Cine Bélico para la revista Historia y Vida: "Las guerras del siglo XX". ${ }^{35}$

En octubre de 1994, la Universidad Complutense de Madrid inicia las Primeras Jornadas Internacionales de Historia y Cine, cuya conferencia inaugural imparte J. M. Caparrós Lera: "El cine como documento histórico". Esta actividad científico-divulgativa continuaría cada año, bajo el impulso de los hoy catedráticos Julio Montero y María Antonia Paz, que editarían distintos libros especializados, recogiendo las ponencias. Constatamos sólo sus títulos más significativos: Historia y Cine: Realidad, ficción y propaganda ${ }^{36}$, Ver cine. Los públicos cinematográficos en el siglo $X X^{37}$, Por el precio de una entrada. Estudios sobre la historia social en el cine ${ }^{38}$ y El cine cambia la historia ${ }^{39}$; aparte de la obra fundamental de estos autores: El cine informativo (18951945). Creando la realidad..$^{40}$

Pero volvamos a la cronología. En mayo de 1995, también me tocó inaugurar el curso sobre Historia Contemporánea de España y Cine, organizado 
en la Universidad Autónoma de Madrid, con una conferencia titulada "Relaciones Historia-Cine en el contexto español". Con las ponencias presentadas, su coordinador publicó un libro: Aitor Yraola (comp.), Historia Contemporánea de España y Cine. ${ }^{41}$ Esta introducción -origen del presente artículo- dio lugar al seminario que impartí en el XXXII Curso de Cinematografía en la Universidad de Valladolid (agosto).

En octubre del mismo año, ya como Profesor Asociado de la Universidad de Barcelona, inicié la asignatura Historia Contemporánea y Cine, la cual ha continuado hasta hoy y ha sido aceptada en el Plan de Bolonia. Asignatura que, con este título y similar programa, pusieron en sus planes de estudios diversas universidades: Universidad del País Vasco, Universidad de Granada y Universidad de Santiago de Chile. Asimismo, inicié un Curso de Doctorado, titulado Cinema com a testimoni de la societat contemporània, que generaría nuevas tesis doctorales. Hasta hoy, han sido 14 las tesis realizadas por los miembros de FILM-HISTORIA.

Por otra parte, con motivo del Centenario del Cine, la revista Historia 16 nos encargó un dossier conmemorativo, que redactó el grupo de FILMHISTORIA: "Cien años de cine". ${ }^{42}$

1996 se abre con el Primer Film-Història Debat en torno una película sobre la Guerra Civil española, Tierra y libertad (Ken Loach, 1995), que organizamos en la Universidad de Barcelona, con la participación de cinco especialistas y la asistencia de más de 200 alumnos (enero). El segundo debate lo dedicamos a las Brigadas Internacionales, con asistencia de varios brigadistas e historiadores y unos 500 alumnos. Seguidamente, presentamos en el I Encuentro de Historiadores de Cine Local (Santander) el tercer libro de la citada colección "Film-Historia": Cine Español. Una historia por autonomías, I. ${ }^{43} \mathrm{El}$ segundo volumen se publicaría en 1998.

En octubre del mismo año, Magí Crusells y J. M. Caparrós Lera presentan la ponencia "Las Brigadas Internacionales y la Guerra Civil española en la pantalla", en las Jornadas sobre la Guerra Civil y las Brigadas Internacionales, celebradas en la Universidad Castilla-La Mancha (Albacete). Un año después, Magí Crusells defendería su tesis doctoral sobre Las Brigadas Internacionales en el cine documental, publicada después como libro.

1997 es otro año de reconocimiento de las interrelaciones Historia y Cine: la revista Anthropos. Huellas del conocimiento, editada en Barcelona, publica un número monográfico titulado "José María Caparrós Lera: Cine e historia. Una propuesta de docencia e investigación"; 44 mientras que la revista Historia, Antropología y Fuentes Orales publica un dossier sobre "Cine e Historia" ${ }^{45}$, redactado también por el equipo de FILM-HISTORIA, que presentamos en el Museu del Cinema (Girona). 
Ese mismo año, el autor del presente artículo - con los profesores Hueso y Monterde, tercer pionero de la implantación en España de las relaciones Historia y Cine - obtiene por concurso-oposición la plaza de Profesor Titular de Historia Contemporánea y Cine de la Universidad de Barcelona, al tiempo que publica su manual 100 películas sobre Historia Contemporánea ${ }^{46} \mathrm{y}$ un libro de prácticas: La guerra de Vietnam, entre la historia y el cine. ${ }^{47}$

En 1998, el profesor Santiago de Pablo -actualmente catedrático de Historia Contemporánea y especialista en el tema que nos ocupa- inicia unas "Jornadas de Historia a través del Cine", que tendrán continuidad hasta hoy, en la Universidad de País Vasco (octubre). Asimismo, cada año edita las ponencias que acompañan a las películas programadas en volúmenes monográficos.

Por otro lado, en la Universidad de Barcelona organizamos el III FilmHistòria Debat, dedicado a los refugios y bombardeos de Barcelona, con la proyección de un vídeo realizado por alumnos de la referida asignatura "Historia Contemporánea y Cine", con la participación de diversos protagonistas e historiadores. Por último, J. M. Caparrós Lera presenta la ponencia Camuflage ideológico del franquismo: "Raza" (1941-1950), manipulación de un film de propaganda política, en el X International Oral History Conference, celebrado en Río de Janeiro por la Fundaçao Getúlio Vargas (agosto). Y el mismo profesor es requerido para impartir el curso titulado "El cine como testimonio de la sociedad", en el Colegio Mayor Albalat de la Universidad de Valencia (noviembre).

1999: el grupo FILM-HISTORIA es contratado para coordinar el ciclo de cine Cinema i propaganda a les guerres del segle XX, para la exposición "Rendeix-te! Octavetes i guerra psicológica al segle XX", organizado por el Centre de Cultura Contemporània de Barcelona (CCCB), y a la vez publicamos un número monográfico de nuestra revista.

En junio, Rafael de España y Caparrós Lera imparten sendas conferencias sobre las relaciones Historia y Cine en España, en el IX Congreso Internacional de la FIEALC: El Mediterráneo y América Latina, celebrado en la Universidad de Tel Aviv (junio). Y el segundo es invitado como Profesor visitante para impartir un seminario sobre "El cine como fuente histórica y medio didáctico", en la Universidad Católica de Valparaíso (Chile), y dicta la ponencia Exilio y Cine, en otro seminario organizado por la Universidad de Santiago de Chile (noviembre). Y a final de año, J. M. Caparrós y Sergio Alegre publican la "Metodología Film-Historia" -base de las investigaciones del Centro- en la revista de la Universidad de Valladolid: "Análisis histórico de los films de ficción". ${ }^{48}$

Asimismo, en el curso académico 1999-2000, FILM-HISTORIA organiza un Posgrado en la Universidad de Barcelona: Cinema i Societat, y se integra como grupo en el Parc Científic de Barcelona. Asisten 12 alumnos 
(5 extranjeros) y entrega los diplomas oficiales el cineasta Bigas Luna (mayo 2000). En junio, J. M. Caparrós presenta la ponencia titulada Una propuesta de clasificación de películas históricas, en la XI International Oral History Conference, celebrada en la Universidad del Bósforo (Estanbul). En agosto, con la profesora María Antonia Paz, imparte un seminario sobre "Historia Contemporánea y Cine", en la Universidad de la Sabana (Colombia). Seguidamente, el mismo profesor dicta dos ponencias: Le cinéma espagnol sous le régime de Franco (1939-1975). Luis G. Berlanga: "Bienvenido Mr.Marshall" (1952) et "Calabuch" (1956), en la Conferencia Internacional sobre "Cinéma et Histoire. Un pont sur le Méditerranée", organizada en Jerusalén por el especialista Shlomo Sand;49 y El Joven Cine español, ante el nuevo milenio, en el Simposio Internacional "España en el siglo XXI: Literatura, Arte y Cultura", organizado por la Ohio State University (Columbus). En octubre de 2000, al grupo FILM-HISTORIA le encargan la coordinación de otro ciclo de cine, en el Simposio Internacional sobre "Los Exilios en el mundo del siglo XX", organizado por el Departamento de Historia Contemporánea de la UB. Y a tal fin, editamos otro número monográfico de la revista.

En junio de 2001, FILM-HISTORIA coordina un Simposio sobre El cine, quinto poder. La influencia de la escuela soviética en el nuevo cine latinoamericano, en el X Congreso Internacional de la FIEALC, celebrado en la Academia de Ciencias de Moscú y organizado por el Instituto de Latinoamérica en Rusia. A continuación, el profesor Caparrós Lera es becado por el Ministerio de Educación y Cultura español para participar en el curso The Young Spanish Cinema: From Almodóvar to the New Century, celebrado en la University of Wyoming (Laramie), donde imparte la conferencia inaugural sobre "El cine español actual" (julio). Asimismo, el mismo profesor es invitado por el también especialista Emilio C. García Fernández -autor del libro Cine e Historia. Las imágenes de la historia reciente ${ }^{50}$ - a colaborar en el monográfico que edita la Universidad Complutense de Madrid: "Catalunya y su historia, en la pantalla"; 51 mientras Rafael de España y Magí Crusells hacen lo propio en la revista que edita el catedrático Santiago de Pablo, en la Universidad del País Vasco: "El cine nazi: temas y personajes" 52 y "Franco en el cine documental español"53, en Historia Contemporánea, núm. 22 (2001), respectivamente.

Ese mismo año, la revista Film-Historia deja de publicarse en papel, para continuar editándose en formato digital, con el título de Filmhistoria Online.${ }^{54} \mathrm{Al}$ mismo tiempo, FILM-HISTORIA coordina un curso de verano "Els Juliols de la UB"- sobre L'Espanya de Franco vista pel cinema del seu temps, e inicia la denominada "Tribuna del Cine Español", que inauguraría el cineasta José Luis Guerín (diciembre 2001). En 2002, protagoniza esa Tribuna José Luis Borau, mientras que el nuevo curso de verano se titula $L$ 'Espanya de Franco vista pel cinema de la democràcia (julio). Y en 2003, "Els Juliols 
de la UB" lo dedicarán a L'oposició al franquisme a través de cinema, y la "Tribuna del Cine Español" la protagoniza David Trueba, con motivo del film Soldados de Salamina (2002).

Nuevas participaciones en congresos: ponencia de La Historia a través del Séptimo Arte, en el V Congreso Internacional de Historia, organizado por la Universidad de Piura (Perú), en abril de 2003; comunicación "Los niños de Rusia”, una muestra de Historia Oral, en el X Congreso Internacional de la Asociación Española de Historiadores del Cine, celebrado en la Universidad de Granada; ${ }^{55}$ e impartición del curso monográfico "El cine como documento didáctico para la enseñanza-aprendizaje" de la Historia Contemporánea", en el CAP de Pamplona, organizado por el Departamento de Educación del Gobierno de Navarra, al que asisten 32 profesores de Geografía e Historia y de Lenguas Clásicas. ${ }^{56}$

Estos años 2004 y 2005, Ediciones UB publica dos nuevos libros de investigación en la colección "Film-Historia": Minorías en el cine. La etnia gitana en la pantalla, original de José Ángel Garrido; y Balcázar Producciones Cinematográficas. Más allá de Esplugas City, de Rafael de España y Salvador Juan i Babot. Y en 2006, José María Caparrós presenta otras dos comunicaciones: Ediciones Antifascistas, una productora vasco-barcelonesa en la Guerra Civil española (1937-1938), en el XI Congreso Internacional de la Asociación Española de Historiadores del Cine, organizado por la Filmoteca de Andalucía (Córdoba); y La producción cinematográfica española durante la Guerra Civil, en el Congreso Internacional 1936-39: La Guerra Civil Española, organizado por la UNED (Madrid), y preside una mesa; mientras Magí Crusells hace lo propio con otra comunicación titulada La producción cinematográfica extranjera en torno a la Guerra Civil (noviembre).

2007. Tres nuevos libros de la colección "Film-Historia": Brumas del franquismo. El auge del cine negro español (1950-1965), de Francesc Sánchez Barba; De La Mancha a la pantalla. Aventuras cinematográficas del Ingenioso Hidalgo, de Rafael de España; y Empezaré contando el final. Cine en blanco y negro del siglo $X X$, de José Ángel Garrido, todos doctores del grupo FILMHISTORIA. También nació una nueva revista especializada, editada por la Universidad de Alicante: Quaderns de cine, cuyo primer número estuvo dedicado a "Cine y ensenyament", con diversos artículos sobre la utilización de las películas en el aula, entre ellos Enseñar la historia contemporánea a través del cine de ficción ${ }^{57}$, original de J. M. Caparrós Lera. Asimismo, la revista pedagógica Making $O f^{58}$ dedicó otro monográfico a "Cine e Historia", con unas valiosas guías didácticas.

Este mismo año, la Universidad Carlos III de Madrid, bajo la dirección de la profesora Gloria Camarero - editora del libro especializado La mirada que habla. Cine e ideologías ${ }^{59}$ - organiza el I Congreso Internacional de Historia 
y Cine. Las Actas se publican al año siguiente, bajo el título de La ventana indiscreta. La Historia desde el Cine.$^{60}$ El profesor Caparrós Lera dictaría en ese congreso la ponencia Grandes acontecimientos históricos contemporáneos en el cine; mientras hace lo propio en el III Congreso Internacional sobre Historia de la Transición en España (1975-1982): La contribución del cine en la reforma política española, organizado por la Universidad de Almería (noviembre).

El Ministerio de Investigación y Ciencia concede a los profesores Ángel Luis Hueso, José María Caparrós, Gloria Camarero, Rafael de España, Xosé Nogueira y Beatriz de las Heras un proyecto I+D titulado "Modelos de Interpretativos del cine histórico español", que dará lugar a nuevas investigaciones en el campo de las interrelaciones Historia-Cine, además de la celebración de sendos nuevos Congresos Internacionales de Historia y Cine, el II en la Universidad Carlos III de Madrid ${ }^{61}$, y el III en la Universidad de Santiago de Compostela.

2009. Dos nuevos libros de la colección "Film-Historia": la obra colectiva Historia(s), teorías y cine. 23 entrevistas; y el diccionario Directores de cine en Catalunya: de la A a la Z, original de Magí Crusells. Estos libros, al igual que los anteriores y los números de la revista Filmhistoria Online, están "colgados" en la red. ${ }^{62}$ Y con motivo del aniversario de la muerte de Stanley Kubrick, Guillem Batlle coordina la exposición Kubrick, 10è aniversari, con exhibición de fotografías y pósters de Senderos de gloria (Paths of Glory, 1957).

En 2010, la Universidad de Barcelona rinde homenaje al grupo FILMHISTORIA, con la edición del libro Historia \& Cinema, 25 aniversario del Centre d'Investigacions Film-Història, en el que colaboran 19 profesores españoles y extranjeros, todos especialistas en las relaciones Historia-Cine. Asimismo, Tomás Valero, otro de los miembros de este centro y autor del portal CineHistoria, dedicado a la utilización del cine como medio didáctico ${ }^{63}$, publica el libro Historia Contemporánea de España vista por el cine, donde analiza 36 películas clave de nuestro cine que reflejan el devenir de la sociedad española (desde la Guerra de la Independencia hasta estos últimos años).

Ese mismo 2010, FILM-HISTORIA organiza dos nuevas exposiciones: La mirada del samurái. Los dibujos de Akira Kurosawa (AlhóndigaBilbao), con diversas actividades y conferencias paralelas; y Cinema en temps de guerra, exili i repressió 1936-1975 (Memorial Democràtic), las cuales tendrán su continuidad en 2011, en el Museo ABC de Madrid y en el curso especializado de "Els Juliols de la UB", con la edición de sendos catálogos.

Nuevas comunicaciones del profesor Caparrós sobre el tema que nos ocupa: ¿Es posible explicar la Historia con el Cine?, en el IV Curso de Cine e Historia, organizado por la Universidad de Huelva ${ }^{64}$; y La sección del PSUC (1937-1938) durante la Guerra Civil española, en el XIII Congreso Internacional de la Asociación Española de Historiadores del Cine, celebrado 
en Santiago de Compostela ${ }^{65}$. Por su parte, Magí Crusells presentaría en el mismo Congreso, con Ángel Morales Santos, la comunicación titulada Mateo Santos Cantero: aportaciones cinematográficas a su biografía.

En abril de 2011, el autor de este artículo obtiene por oposición la Cátedra de Historia Contemporánea y Cine de la Universidad de Barcelona, consolidando con ello las interrelaciones Historia y Cine, en España. Hasta aquí, pues, el panorama de la materia que ha sido objeto de nuestro travelling histórico; mientras preparamos el IV Congreso Internacional de Historia y Cine: Memoria Histórica y Cine Documental, en la misma Universidad de Barcelona, que celebraremos del 5 al 7 de septiembre del año 2013.

\section{NOTAS}

${ }^{1}$ Heredero del historiador alemán Siegfried Kracauer (From Caligari to Hitler. A Psycological History of German Cinema. Princeton: University Press, 1947), sus primeros artículos sobre el tema se publicaron en la década de los sesenta, y después algunos vieron la luz en sus libros: Analyse de film, analyse de sociétés. Un source nouvelle pour l'Histoire. París: Hachette, 1975; Cinema et Histoire. 2 ed. Actualizada. París: Gallimard, 1993; Historia contemporánea y cine. Barcelona: Ariel, 2000, (prologada por el autor de este artículo) y El cine, una visión de la historia. Madrid: Akal, 2008.

${ }^{2}$ Cfr. Paul Smith (ed.). The Historian and Film. Cambridge: University Press, 1975, donde también escribió Marc Ferro, en España se editaría al año siguiente un primer texto titulado La historia a través del cine. Madrid: Artedita, 1976, del argentino Ramón Barco, una obra de recopilación que no aguanta una crítica rigurosa.

3 MONTÓN, A. L. El cine, fuente histórica del siglo XX. Universidad Complutense de Madrid, 1974.

4 Vid. también los siguientes libros de este autor: Historia de los géneros cinematográficos, I. El cine histórico.Valladolid: Heraldo, 1976; El cine y la historia del siglo XX. Santiago de Compostela: Universidad de Santiago, 1983 -primera síntesis de su citada tesis doctoral-; Los géneros cinematográficos. Materiales filmográficos y bibliográficos. Bilbao: Mensajero, 1983 -que posee también un capítulo sobre el cine histórico-; El cine y el siglo XX. Barcelona: Ariel, 1998, Catálogo de cine español. Películas de ficción 1941-1950. Madrid: Cátedra/Filmoteca Española, 1998. Entre otros estudios más específicos, y las Actas del III Congreso Internacional de Historia y Cine: Modelos de interpretación para el cine histórico, que dirigió en el mes de noviembre de 2011 (en prensa).

5 Posteriormente, Drac Màgic organizó ciclos más amplios, interdisciplinares desde 1981, con películas "ilustrativas" de las materias de Historia, Filosofía, Literatura, Ética, Arte y Música a través del cine. Cfr. los programas y el artículo de José Enrique Monterde, "Cinema i Història", en Butlletí del Col·legi Oficial de Doctors i Llicenciats de Catalunya. Barcelona: julio-septiembre 1985, p. 41-42; labor que resumirían sus componentes en un libro que aparecería muchos años después: J. E. Monterde. et al. La representación cinematográfica de la historia. Madrid: Akal, 2001.

6 Vid., por ejemplo, los dossiers correspondientes a Espartaco, El Gatopardo, Galileo, Paseo por el amor y la muerte, En busca del fuego y La verdad sobre el caso Salvolta. Después 
editarían la revista especializada Aula-Vídeo, que no tendría demasiada continuidad (4 números). Sin embargo, en el núm. 1 apareció un valioso dossier sobre "La Edad Moderna en el cine", original del profesor Ramon Alquézar, que se adelantó en años al libro especializado de Juan Manuel Santana y Germán Santana, Las representaciones de la Historia Moderna en el cine. Las Palmas de Gran Canaria: Anroart, 2008. En este sentido, también es interesante la metodología publicada en aquellos años por Juan C.arlos Flores Auñón, El cine, otro medio didáctico. Introducción a una metodología para el uso del cine como fuente de las Ciencias Sociales. Madrid: Escuela Española, 1982, tesis dirigida por el profesor Ángel Luis Hueso, y el informe elaborado por encargo de la UNESCO, Educación a los Medios, original de los profesores Primitivo Rodríguez Gordillo y José María Caparrós Lera, et al. Madrid: 1979. Un año antes también había visto la luz mi ensayo El cine. Padres y adolescentes. Barcelona: FERT, 1978, que obtuvo el Premio Nacional de Cine Didáctico 1977.

${ }^{7}$ Incluso se publicó un volumen titulado Cine e Historia. Barcelona: Filmoteca Nacional de España, 1977.

${ }^{8}$ Cfr. la crónica de Enric Ripoll-Freixes, "El film com a testimoni històric", en diario Avui. 27 oct. 1977.

9 Como especialista en el tema, ya había publicado por esas fechas $E l$ cine republicano español 1931-1939. Barcelona: Dopesa, 1977, antes de editar mi tesis doctoral como libro: J. M. Caparrós Lera. Arte y Política en el Cine de la República 1931-1939. Barcelona: Siete y Media/Universidad de Barcelona, 1981. Y los más recientes artículos publicados en las revistas Historical Journal of Film, Radio and Television. v. 5, n. 1, Film and History. v. 16, n. 2 y New Orleans Review. v. 14, n. 1. De hecho, nunca abandonaría esa especialidad, con continua asistencia a congresos, publicación de comunicaciones, edición de ensayos, conferencias, organización de ciclos y exposiciones. La última, comisariada con el historiador Magí Crusells, Cinema en temps de guerra, exili i repressió (1936-1975), cuyo catálogo es un libro: Barcelona, Memorial Democràtic, 2010.

${ }^{10}$ Inspirado en esos textos, el profesor mallorquín S. Serra Busquets publicó una "Programació didàctica de la Història Contemporània a través del Cinema". Maina, n. 4. Palma de Mallorca, p. 81-85, 1981.

${ }^{11}$ El ciclo más significativo es el monográfico que dedicaron a "La Revolución Francesa", en el que colaboraron especialistas y cuyos films presentaron en los Multicines Chaplin de la ciudad de Palma, editando un cuidado folleto.

${ }^{12}$ Cfr. sus Memorias de Actividades, con la programación completa. La correspondiente al curso 1985-86 ofrece un resumen de la tarea llevada a cabo en esa Universidad gallega por el Departamento de Historia del Cine que dirige en profesor Hueso.

${ }^{13}$ Vid. la memoria publicada en la sexta edición: J. M. Caparrós Lera (ed.), 6 anys d'Història $i$ Cinema a la Universitat de Barcelona. Barcelona: Facultat de Geografia i Història, 1987, con artículos originales de Marc Ferro, Ángel Luis Hueso, Miquel Porter-Moix, entre otros. Sin embargo, mis actividades docentes en torno a este campo especializado ya habían comenzado años antes: desde 1977 impartí un seminario titulado "Interrelacions Història i Cinema", en el Departamento de Historia del Arte de la Universidad de Barcelona, como Colaborador de Cátedra, donde continuaría hasta que defendí mi citada tesis doctoral y obtuve en febrero de 1982 la plaza de Profesor Ayudante de la asignatura "Història de la Cinematografia Clàssica", que impartía mi maestro, el profesor Miquel Porter-Moix. Un balance de la actividad desarrollada en ese seminario puede encontrarse en J. M. Caparrós Lera, "Una propuesta en torno a las relaciones Historia-Cine". Cinematógrafo, n. 1, Gijón: Actas del I Encuentro de la 
AHCEE, 1989, p. 37-65, donde no sólo aparece el listado de trabajos desarrollados durante esos años pioneros, sino la metodología de investigación empleada para la realización de tesis doctorales y tesinas de licenciatura.

${ }^{14}$ Cfr. los artículos de la Delegación de Sabadell. Butlletí del Col-legi de Doctors i Llicenciats de Catalunya, n. 50-54. enero-marzo 1985-1986.

${ }^{15}$ Fruto de esa manifestación, un año más tarde se editaría un libro de colaboraciones: ROMAGUERA, Joaquim; RIAMBAU, Esteve(eds.). La Historia y el Cine. Barcelona, Fontamara, 1983, que es la primera síntesis española sobre el tema.

${ }^{16}$ Tarragona: PPU, 1985. El profesor Cano es otro de los pioneros en este terreno especializado. Su tesis doctoral data de 1973: Influencia del Mundo Clásico en la Historia de la Cinematografía. Universidad Autónoma de Barcelona. Vid., no obstante, las más recientes aportaciones de los también especialistas Rafael de España, El Peplum, La Antigüedad en el cine. Barcelona: Glénat, 1998 y La pantalla épica. Los héroes de la Antigüedad vistos por el cine. (Madrid: T\&B, 2009; y ARCINIEGA, Alberto Prieto. La Antigüedad filmada. Madrid: Ediciones Clásicas, 2004) y La Antigüedad a través del cine. Barcelona: UB, 2010.

${ }^{17}$ Cfr. los artículos de Juan Cal, "Cómo explicar la Historia, de cine", y R. Fernández, A. Sánchez y P. Tovar, "El cine al servicio de la historia y la literatura”, en diario Segre, 11 dic. 1983.

${ }^{18}$ Disponible en: <www.ub.edu/filmhistoria $>$.

${ }^{19}$ Historia del Cine. Época muda (1895-1930). Barcelona: Casals, 1983.

${ }^{20}$ MONTERDE, José Enrique. Cine, historia y enseñanza. Barcelona: Laia, 1986.

${ }^{21}$ Vid. el informe de M. Martínez, A, Pagans, I. de Puig y J. M. Terricabras. "Una experiencia interdisciplinar per a COU”, Butlleti del Col-legi Oficial de Doctors i Llicenciats, n. 54, eneromarzo 1986, p. 42-43.

22 nov./dic., 1984.

${ }^{23}$ Cfr. "Imágenes e Historia”, II Semana de Cine Español. Murcia: Universidad/Ayuntamiento de Murcia, 1985, p. 20-23.

${ }^{24}$ CAPARRÓS LERA, J. M.; ESPAÑA, R. The Spanish Cinema: an historical approach. Barcelona: Film-Historia, 1987.

${ }^{25}$ Archivo Histórico Nacional: Salamanca, oct. 1988.

${ }^{26}$ Université Lumière: Lyon, feb. 1989.

${ }^{27}$ Frostburg University: Maryland, aug. 1989.

${ }^{28}$ Extra, n. 58, oct. 1990.

${ }^{29}$ Vid. Actes del Congrés Internacional sobre Guerra, Cinema i Societat, en Film-Historia, v. III, n. 1-2, 1993.

${ }^{30}$ ALEGRE, Sérgio et al. El cine en Cataluña: una aproximación histórica. Barcelona: PPU, 1993.

${ }^{31}$ Este historiador norteamericano, otro de los grandes especialistas en Historia y Cine, impartió un seminario en el Centre d'Investigacions Film-Història -con una Beca Fullbright- y clases de la asignatura "Història Contemporània i Cinema" en la Universidad de Barcelona, en inglés. Y le publicamos en castellano su libro El pasado en imágenes. El desafío del cine a nuestra idea de la historia. Barcelona: Ariel, 1997, prologado por el profesor Ángel Luis Hueso. 
${ }^{32}$ v. 98 , n. 4, oct. 1994, p. 1175-1177.

${ }^{33}$ Portland: feb. 1994.

${ }^{34}$ Universidad de Guadalajara: México, marzo 1994.

${ }^{35}$ Extra n. 72, marzo 1994.

${ }^{36}$ MONTERO, Julio; PAZ, María Antonia. Historia y Cine: realidad, ficción y propaganda. Madrid: Universidad Complutense, 1995.

${ }^{37}$ Madrid: Rialp, 2002.

${ }^{38}$ MONTERO, Julio; CABEZA, José (org.). Por el precio de una entrada: estudios sobre la historia social en el cine. Madrid: Rialp, 2005.

${ }^{39}$ MONTERO, Julio; RODRÍGUEZ, Araceli. El cine cambia la historia. Madrid: Rialp, 2005.

${ }^{40}$ MONTERO, Julio; PAZ, María Antonia. El cine informativo (1895-1945): creando la realidad. Barcelona: Ariel, 2000.

${ }^{41}$ YRAOLA, Aitor. Historia Contemporánea de España y Cine. Madrid: Universidad Autónoma, 1997.

${ }^{42}$ n. 234, oct. 1995, p. 21-121.

${ }^{43}$ CAPARRÓS LERA, J. M. (Coord.). Cine Español: una historia por autonomías. Barcelona: PPU, 1996.

${ }^{44}$ n. 175.

${ }^{45}$ n. 18.

${ }^{46}$ CAPARRÓS LERA, J. M. 100 películas sobre Historia Contemporánea. Madrid: Alianza, 1997. 2 ed. actualizada, 2004.

${ }^{47}$ CAPARRÓS LERA, J. M. La guerra de Vietnam, entre la historia y el cine. Barcelona: Ariel, 1998.

${ }^{48}$ CAPARRÓS LERA, J. M.; ALEGRE, Sergio. Metodología Film-Historia. Cuadernos Cinematográficos. n. 10, p. 7-26, 1999.

${ }^{49}$ Su libro básico también fue editado en España: El siglo XX en pantalla: cien años a través del cine. Barcelona: Crítica, 2005.

${ }^{50}$ GARCÍA FERNÁNDEZ, Emilio C. Cine e Historia: las imágenes de la historia reciente. Madrid: Arco, 1998.

${ }^{51}$ CAPARRÓS LERA, J. M. Catalunya y su historia, en la pantalla. Cuadernos de Historia Contemporánea. n. 23, p. 103-124, 2001.

${ }^{52}$ p. 151-178.

${ }^{53}$ p. $215-231$.

${ }^{54}$ Disponible en: <www.pcb.ub.es/filmhistoria $>$.

${ }^{55}$ feb. 2004.

${ }^{56}$ sept. 2004.

${ }^{57}$ CAPARRÓS LERA, J. M. Enseñar la historia contemporánea a través del cine de ficción. p. 25-35.

${ }^{58}$ n. 48, Barcelona, 1997. 
${ }^{59}$ CAMARERO, Gloria. La mirada que habla: cine e ideologías. Madrid: Akal, 2002.

${ }^{60}$ CAMARERO, Gloria; HERAS, Beatriz de las; CRUZ, Vanessa de (eds.). La ventana indiscreta: la Historia desde el Cine. Madrid: JC, 2008.

${ }^{61}$ Las nuevas Actas ya vieron la luz como libro: CAMARERO, Gloria (ed.). Vidas de Cine. El biopic como género cinematográfico. Madrid: T\&B, 2011.

${ }^{62}$ Disponible en: <www.publicacions.ub.es/bibliotecadigital/cinema $>$.

${ }^{63}$ Disponible en: $<$ www.cinehistoria.com $>$.

${ }^{64}$ nov. 2010.

${ }^{65}$ marzo 2011.

Artigo recebido em junho de 2012. Aceito em agosto de 2012. 